\title{
A summary of Blastocystis subtypes in North and South America
}

\author{
Paula Andrea Jiménez ${ }^{1,2+}$, Jesús Eduardo Jaimes ${ }^{1+}$ and Juan David Ramírez ${ }^{1 *}$ (])
}

\begin{abstract}
Background: Blastocystis is a stramenopile of worldwide significance due to its capacity to colonize several hosts. Based on its high level of genetic diversity, Blastocystis is classified into global ribosomal subtypes (STs). The aim of this study was to conduct a summary of Blastocystis STs and depict their distribution throughout North and South America; we did this by assembling maps and identifying its most common $18 \mathrm{~S}$ alleles based on diverse studies that had been reported all over the continent and whose Blastocystis-positive samples were obtained from numerous hosts.

Results: Thirty-nine articles relating to nine countries from the American continent were considered, revealing that ST1 (33.3\%), ST2 (21.9\%), ST3 (37.9\%), ST4 (1.7\%), ST5 (0.4\%), ST6 (1.2\%), ST7 (1\%), ST8 (0.7\%), ST9 (0.4\%), ST12 (0.3\%), Novel ST $(1.1 \%)$ and Mixed STs $(0.2 \%)$ occurred in humans. The STs in other animal hosts were ST1 (6.5\%), ST2 (6.5\%), ST3 (4.7\%), ST4 (7.2\%), ST5 (15.9\%), ST6 (17.3\%), ST7 (3.6\%), ST8 (20.6\%), ST10 (9\%), ST14 (3.6\%), ST17 (1.1\%) and Novel ST (4\%). The countries that presented the most abundant variety of studies reporting STs were the USA with 14 STs, Brazil with 9 STs and Colombia with 8 STs. Additionally, new variants had been described in the last few years, which have increased the prevalence of these subtypes in the countries studied, such as Novel ST (1.1\%) and Mixed STs $(0.2 \%)$ in humans and Novel ST (4\%) in animals.
\end{abstract}

Conclusions: This summary updates the epidemiological situation on the distribution of Blastocystis STs in North and South America and will augment current knowledge on the prevalence and genetic diversity of this protozoan.

Keywords: Blastocystis, Distribution, Diversity, Geographic, North and South America, Subtypes

\section{Background}

Blastocystis, a strict anaerobic protist, has colonized many different animals around the world and can compromise the gastrointestinal tract of domestic and wild animals such as cattle, dogs, cats, reptiles, birds, chickens and rats, among others $[1,2]$. The most probable route of transmission for Blastocystis in both humans and animals is via oral-fecal transmission, based on the molecular epidemiological data for this parasite. The rapid propagation and the ability to survive in different organisms such

*Correspondence: juand.ramirez@urosario.edu.co

†Paula Andrea Jiménez and Jesús Eduardo Jaimes contributed equally to this work

${ }^{1}$ Grupo de Investigaciones Microbiológicas-UR (GIMUR), Departamento de Biología, Facultad de Ciencias Naturales y Matemáticas, Universidad del Rosario, Bogotá, Colombia

Full list of author information is available at the end of the article as humans and animals, probably explains its global distribution [3].

Several studies have described the genetic diversity present in Blastocystis, which has led to its classification as having multiple subtypes (STs) in its different lineages, based on polymorphic regions of its small subunit of the ribosomal RNA gene [4]. Some of these STs are found in different hosts, but others are exclusively in humans [5]. Currently, 17 subtypes are known, of which ST1 to ST9 and ST12 have been identified in humans [6, 7]. In humans from Europe, STs 1, 2, 3 and 4 reportedly occur most commonly [8], whereas ST1, 2 and 3 commonly occur in South America [2, 9]. More than one ST can reportedly colonize humans, and infections with mixed STs have been reported [10].

Blastocystis may cause clinical manifestations [11, 12] such as diarrhea, abdominal pain, irritable bowel syndrome, constipation and flatulence [6], along with 
extraintestinal manifestations such as chronic urticaria [13]. However, these symptoms are not specific from this protist, bearing in mind that polyparasitism is very common in North and South America. It is not known whether these manifestations are associated only with Blastocystis and a specific ST, or multiple parasite colonization. However, recent microbiome studies suggest that Blastocystis colonization is usually associated with a healthy gut microbiota, rather than with gut dysbiosis generally observed in metabolic or infectious inflammatory diseases of the lower gastrointestinal tract. In addition, a metagenomics approach showed that individuals with intestinal microbiota dominated by Bacteroides were much less prone to having Blastocystis-positive stool than individuals with Ruminococcus and Prevotelladriven enterotypes showing that the presence of Blastocystis might be beneficial for the human health. The pathogenicity of this organism is under strong debate, mainly due to a high rate of asymptomatic carriers, the differences in host susceptibility, intestinal microbiota and/or different pathogenic potential of different genetic STs [14-20].

Most of the American continent is considered to have ideal conditions (high rates of poverty, inadequate sanitation in poor populations, internal civil conflicts, high biodiversity and lack of potable water in some regions) for a high prevalence of Blastocystis. Nevertheless, the Blastocystis STs in North and South America are not yet fully understood, given the lack of studies in several of the countries that comprises it. Most is known about its distribution in Colombia, Argentina, the USA, Bolivia, Peru, Brazil and Ecuador [9]. Despite efforts, no consolidation of the metadata has been attempted for the distribution of Blastocystis STs and there is only one revision focused on the STs found in humans from South America [9]. Therefore, we describe herein our summary of the studies published on Blastocystis subtypes in humans and other animals across North and South America. We constructed maps for Blastocystis and were able to identify its most frequent $18 S$ alleles.

\section{Methods}

\section{Literature searches}

We searched for articles reporting on the presence of Blastocystis STs in humans and other animals throughout North and South America in the following databases: PubMed, ScienceDirect and the Integrated Search System of Universidad del Rosario, Colombia. The included keywords were Blastocystis, STs, subtypes, distribution, epidemiology, alleles, molecular, geographic, intestinal parasites, genetic diversity and characterization.

Studies reported in English, Portuguese and Spanish were selected. We geographically limited our searches to studies from North and South America, excluding those that were undertaken outside of the American continent. The information on the articles included their publication dates, summaries and results, and whether the Blastocystis subtype and study system (model animal or human) was mentioned. The inclusion criteria were as follows: articles from which samples were obtained in countries on the American continent, identification of the parasite by one or both parasitological and molecular methods, and Blastocystis subtype analysis. Taking the above into account, approximately 50 articles were found, of which only 39 met the above-stated criteria to be part of this review.

\section{Information extraction}

Two investigators performed data extraction during January and February of 2019; extracting the characteristics of each study, which included the country, exact location of the samples, number of samples, number of samples positive for Blastocystis, host, subtype identification, number of samples per subtype, alleles identified, method used for subtype identification, last name of the first author and year of publication. A Microsoft Excel database was constructed with the information obtained from the articles, in which all the data above-mentioned and variables were added, to tabulate the information in an efficient way (Additional file 1: Table S1). We extracted the information on the variables from each of the articles that met the inclusion criteria for this study. This information was supplemented by searching for the coordinates (latitude and longitude) of the different places where the samples were collected. Thus, the data obtained were built with the QGIS maps program, thereby revealing the distribution of STs in North and South America and the ST variables, the country and the geographical region, with their exact coordinates, which allowed us to locate the specific geographical points for the STs. This was done for the STs that are most prevalent in both humans and animals (ST1, ST2 and ST3). Finally, a map of North and South America was constructed in which all the subtypes of the STs found in this study and their presence in the different countries were taken into account, which allowed us to identify which subtypes occurred in the nine countries that had carried out typing studies.

\section{Results}

Our review of Blastocystis in the different countries of North and South America identified 39 articles that met the selection criteria, for which the distribution of Blastocystis and its subtypes was analyzable. However, only nine countries in North and South America (Argentina [9, 13], Brazil [9, 11, 21-31], Bolivia [9, 32, 33], Colombia [2, 9, 10, 34-37], Chile [38], Ecuador [9, 39], USA [17, 36, 


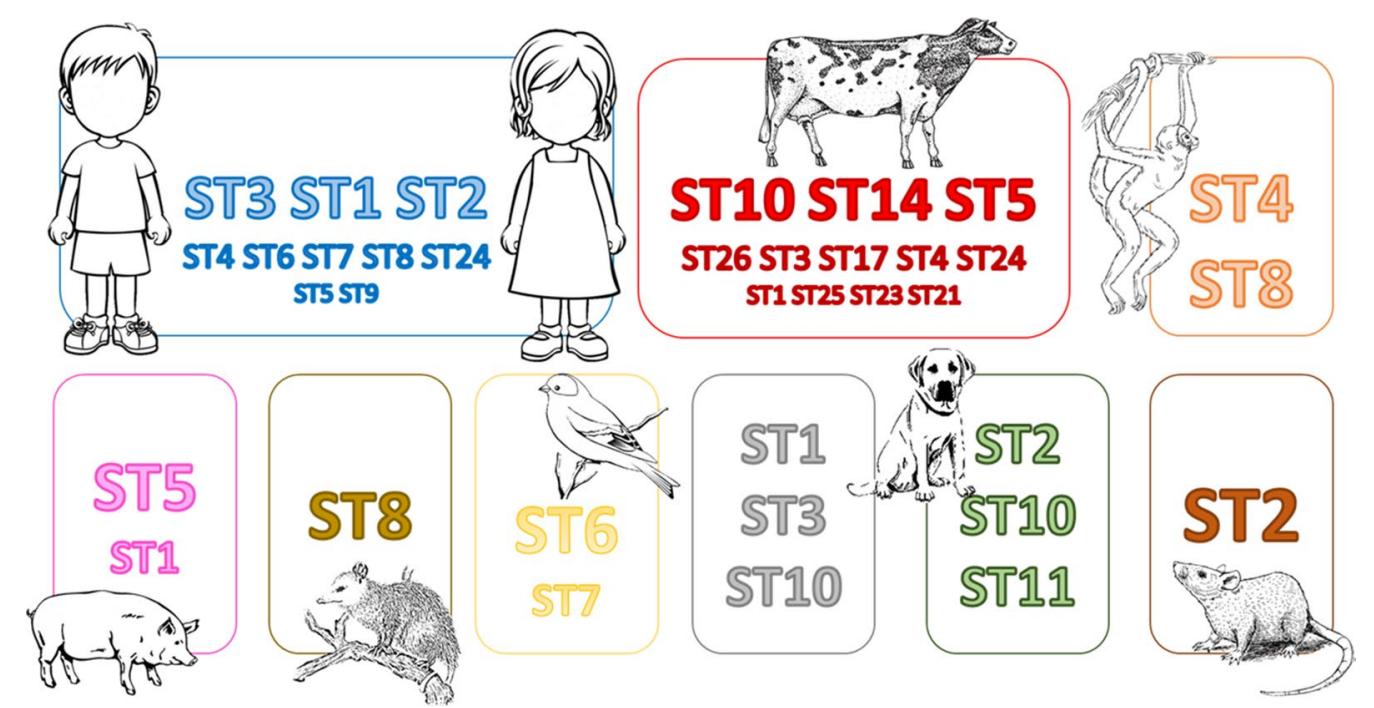

Fig. 1 Blastocystis subtypes found in humans and animals. The boxes show the Blastocystis subtypes per host, and the size of the number is proportional to parasite occurrence. There are vast differences in the prevalence between these as groups for instance. This figure depicts occurrence and not prevalence

40-47], Peru [9] and Mexico [48-50] were found to have carried out this type of study. From these countries, Blastocystis was identified in samples from both human and other hosts. Blastocystis-positive samples were recorded for birds (Gallus gallus domesticus) [2, 28], pigs (Sus scrofa domestica) [26, 36, 41], monkeys (Alouatta spp.) [2, 39], marsupials (Didelphis marsupialis) [2], cattle [2, 26, 36, 41, 44], cats (Felis silvestris catus) [26, 45], dogs (Canis lupus familiaris) [2, 23, 26, 27, 45], sheep (Ovis orientalis aries) [26] and rats (Rattus rattus) [2]. The STs found by host (human or animal) are shown in Fig. 1.

\section{Summary of Blastocystis STs by country}

The Blastocystis distribution throughout North and South America, based on the studies conducted thus far in 9 different countries (USA, Mexico, Colombia, Brazil, Ecuador, Peru, Bolivia, Chile and Argentina), is shown in Fig. 2a, and the composition of the subtype categories is shown in Fig. 2b. The most frequent subtypes (ST1, ST2 and ST3) that were identified in humans and other animals are shown in Fig. 3.

Among the studies conducted in North and South America, the most widespread subtypes we collated were ST1 and ST2, which were present in the samples from eight of the nine countries that were studied [2, 9-11, 17, 21-27, 29-39, 42, 43, 45-50]. Subsequently, ST3 was found in seven of the nine countries [2, 9-11, $13,17,21,23-25,27,30,31,33-37,39,42,43,46-50]$. To a lesser extent, Novel ST was present in five of the nine countries [9, 39], ST4 and ST8 occurred in four countries [2, 9-11, 21, 22, 25, 30, 31, 35-39, 42, 44, 47],
ST6 and ST7 occurred in three countries [2, 9-11, 13, $23,27,28,30,35,50]$, ST5 occurred in two countries [9, 36, 41, 44], while ST9, ST10, ST12 and ST17 occurred in only one of the nine countries that were studied [9, $32,40,44,45]$.

The high occurrence of ST1 led us to build a map (Fig. 3a) georeferencing the Blastocystis-positive sampling sites by country. The map in Fig. 3a shows the ST1-positive samples obtained from humans, which are represented by green points. This ST was identified in studies from Argentina, Bolivia, Brazil, Chile, Colombia, Ecuador, USA and Mexico [2, 9, 11, 13, 21-25, 27, 29-35, 37-39, 42, 43, 46-50]. In addition, positive samples for ST2 shown in panel b of the map in Fig. 3 (represented by yellow points) are limited to Argentina [13], Brazil [9, 11, 21, 22, 24, 27, 29-31], Bolivia [9, 32, 33], Colombia [2, 9, 35, 37], Ecuador [39], Chile [38], USA [38, 46] and México $[49,50]$. The ST3 positive samples, represented in Fig. 3c (violet points), were distributed in Argentina [9, 13], Brazil [9, 11, 21-25, 27, 30, 31], Bolivia [9, 33], Colombia, [2, 9, 34, 35, 37], Ecuador [9, 39], USA [42, 43, 46, 47] and Mexico [48-50].

Likewise, the georeferenced distributions for other hosts are also represented in Fig. 3, where ST1 samples (purple stars) were obtained from Brazilian pigs [26], Colombian cattle [2] and from North American dogs and cats [45]. For ST2 shown in panel b of the map (Fig. 3b) by red stars, the samples were recorded from Colombian dogs and rats [2]. Moreover, ST3 samples, represented in Fig. 3c by pink stars, were limited to Colombian departments [2] and the USA [45]. 


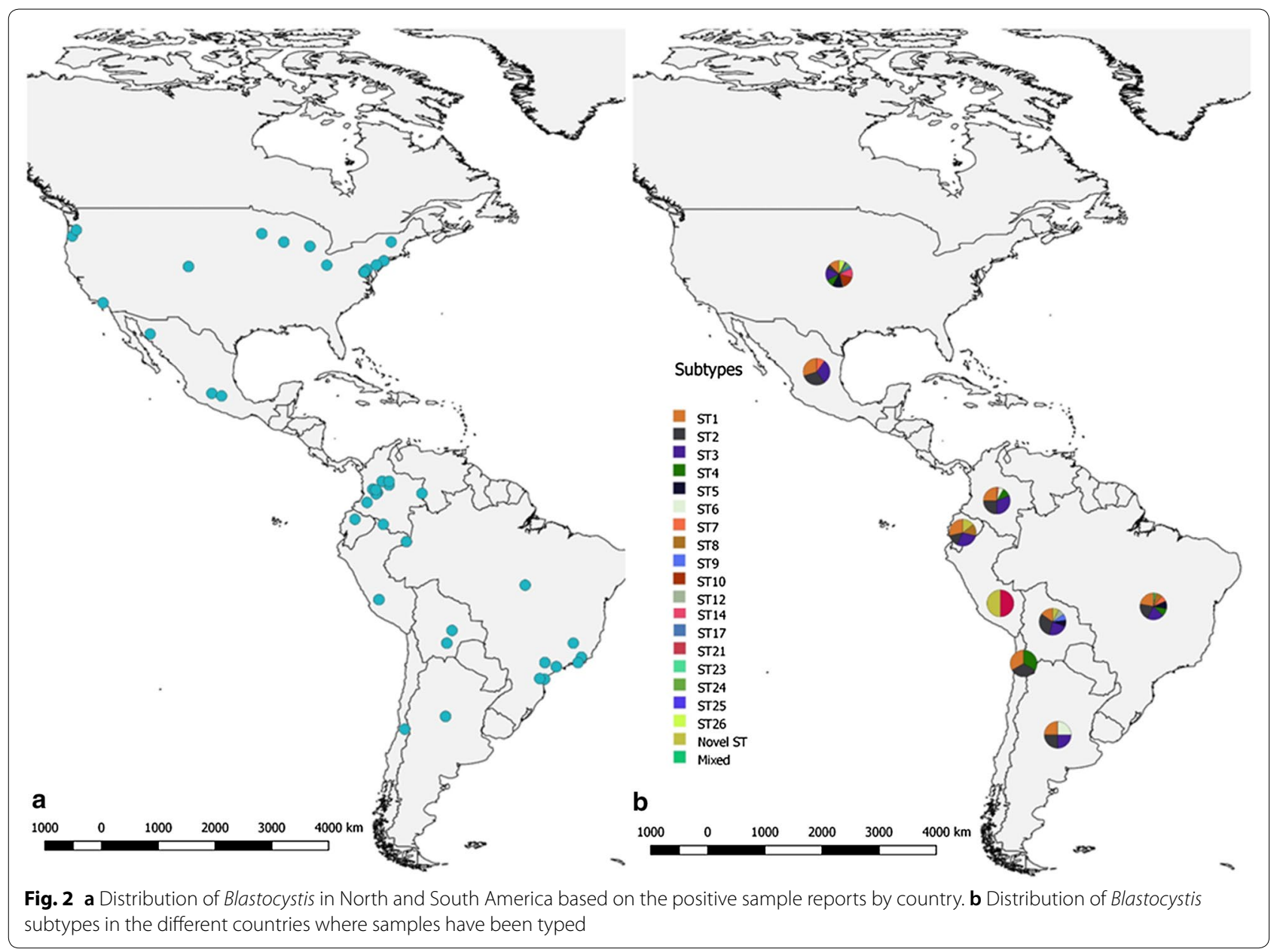

\section{Distribution of Blastocystis STs by hosts}

The STs distribution for humans was as follows: ST1 (615/1847; 33.3\%), ST2 (404/1847; 21.9\%), ST3 (700/1847; $37.9 \%)$, ST4 (31/1847; $1.7 \%)$, ST5 (8/1847; 0.4\%), ST6 (23/1847; 1.2\%), ST7 (18/1847; 1\%), ST8 (13/1847; 0.7\%), ST9 (8/1847; 0.4\%), ST12 (4/1847; 0.3\%), Novel ST (20/1847; 1.1\%) and Mixed STs (3/1847; 0.2\%) (Fig. 2b). In the case of the non-human animals, the distribution was as follows: ST1 (18/267; 6.7\%), ST2 (18/267; 6.7\%), ST3 (13/267; 4.9\%), ST4 (20/267; 7.5\%), ST5 (44/267; 16.5\%), ST6 (48/267; 18\%), ST7 (1/267; 0.4\%), ST8 (56/267; 21\%), ST10 (25/267; 9.4\%), ST14 (10/267; 3.7\%), ST17 (3/267; $1.1 \%)$ and Novel ST (11/267; 4.1\%).

According to the allelic discrimination relating to the identified subtypes in humans, the most frequent alleles in each ST were as follows: ST1 $(a 4,2)$ also found in American cattle $[2,10,11,23,30,35,46]$, ST2 (a9, 12, $15,11,71)$ where a9 was also present in dogs an rats $[2,10,11,23,27,30,33,37,46]$, ST3 $(\mathrm{a} 34,36,37)$ with a34 also in American cattle $[2,9,11,13,23,27,30,35$, $37,46]$, ST4 (a42, a91, a133) where a42 and a133 were found in Alouatta spp. [2, 10, 30, 35, 37], ST6 (a122) also described in chickens [2, 10, 11, 23, 30], ST7 (a96, $106,137,142)[10,23,27]$ and ST8 (a21) and Didelphis marsupialis as well $[2,30]$. The shared alleles led us to hypothesize that they can have an important role in the transmission dynamics of the parasite between different hosts, but this subject is not analyzed in the present study. Additionally, other alleles were identified in smaller amounts $(\leq 10 \%)$ in the STs mentioned: for ST1, other 9 alleles were found; ST2, 4 alleles; ST3, 10 alleles; ST4, 2 alleles; and ST6, 1 allele. This information was obtained from those studies $(n=10)$ in which allelic detection was carried out; however, not all of them used this methodology, so no alleles were identified in some of them. This means that the information shown in Figs. 4 and 5 correspond only to those studies that performed allele typing of the samples obtained in humans and other animals, respectively. 

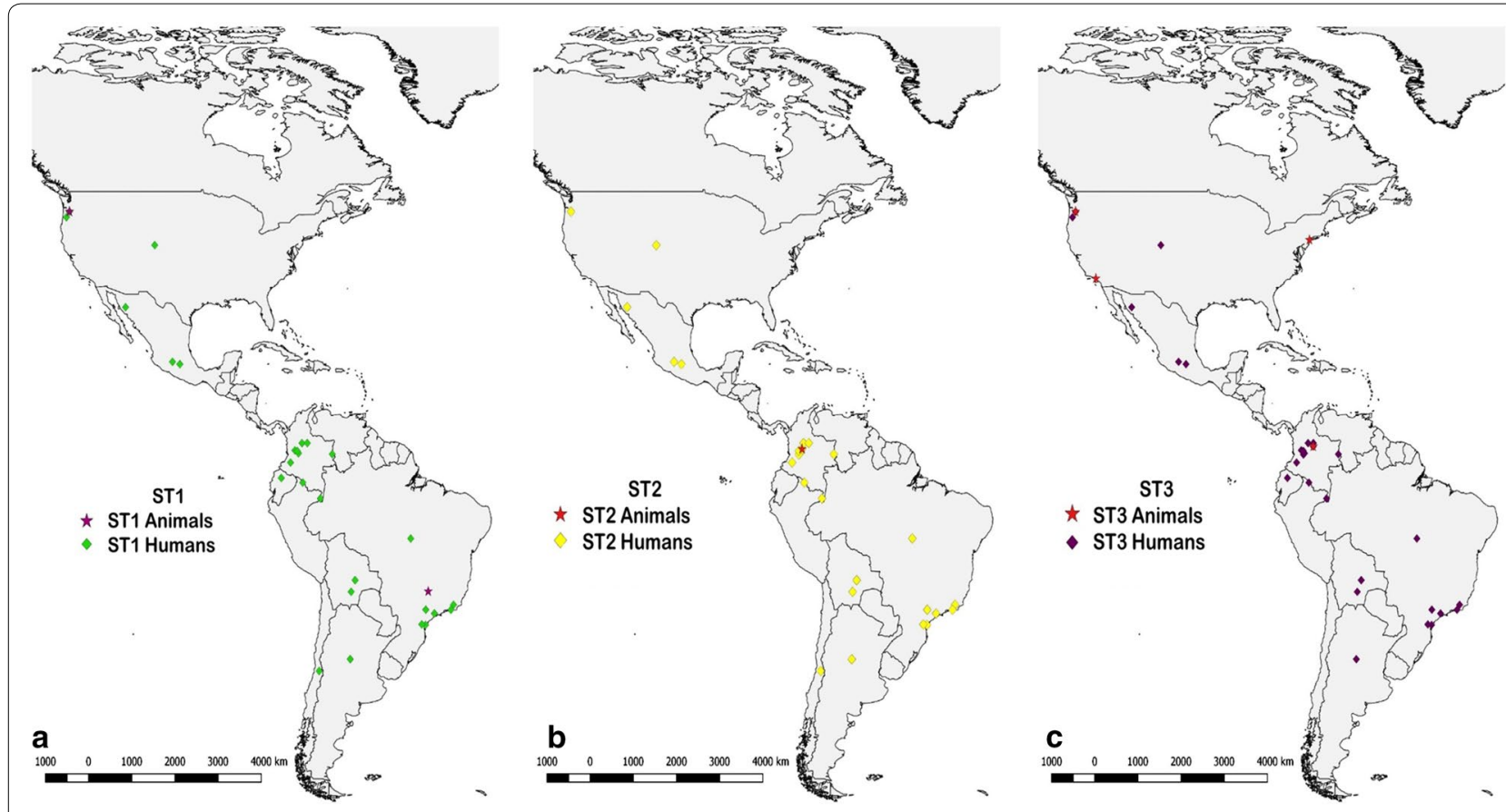

Fig. 3 a Distribution by country of the samples positive for ST1 in humans and other animals. b Distribution by country of the samples positive for ST2 in humans and other animals. c Distribution by country of the samples positive for ST3 in humans and other animals. Abbreviation: ST, ribosomal subtype

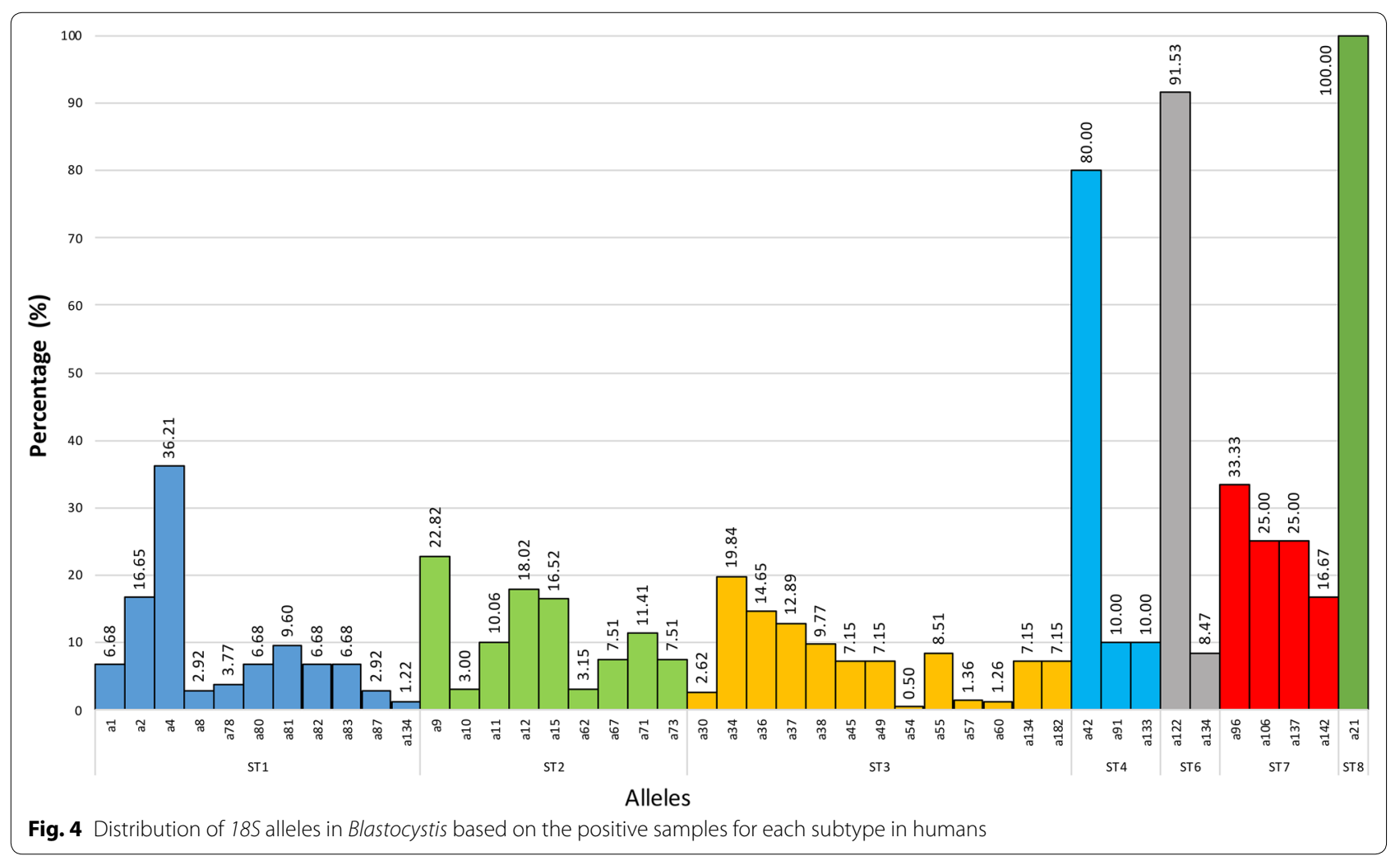




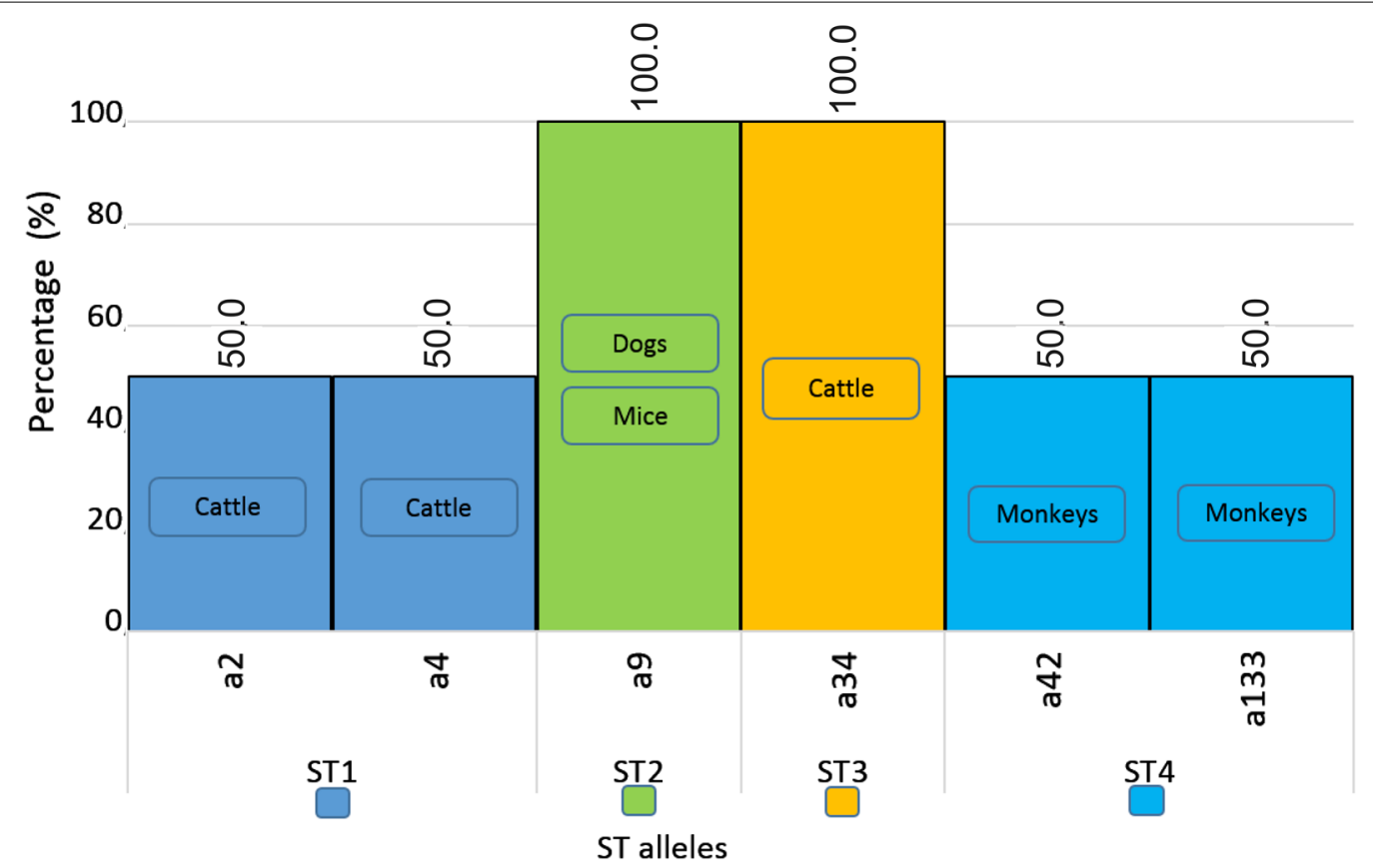

Fig. 5 Distribution of 185 alleles in Blastocystis based on the positive samples for each subtype in cattle, dogs, mice and monkeys

\section{Discussion}

The most recent epidemiological data on the Blastocystis STs in North and South America are limited to reports from specific countries such as the USA, Colombia and Brazil, where the majority of reports originate $[9,10$, $29-31,35,44]$. This prompted us to conduct this review whereby we considered every country in North and South America where Blastocystis has been studied; however, data are not available for many countries. The fact that the majority of reports come from these countries may be related to their higher numbers of investigators. This suggests that more investigators are required in the underrepresented countries so that the true distribution of Blastocystis across North and South America can be elicited.

Considering the above information, this review found that STs 1 to 9 were present in the samples from the North and South American countries that have studied and typed Blastocystis. Although the literature mentions that these STs only colonize humans (Additional file 1: Table S1) [5], this review revealed the presence of these subtypes in other animals such as monkeys (Alouatta spp.), pigs, birds, cats, cattle, dogs, marsupials (D. marsupialis) and rats (Fig. 1). This suggests that these animals might be in contact with humans, either domestically or as farmed animals, making it possible for them to be colonized by an ST that was thought to occur only in humans, as is considered the case with ST3 [21]. This highlights the zoonotic potential of this stramenopile and its ability to colonize different host species, an observation widely reported in different countries in Europe, Africa and Asia [3, 6, 51-59]. This is supported by the $18 \mathrm{~S}$ allele data where multiple alleles are shared between humans and animals.

The present review found that a large number of samples were typed most frequently as ST1, ST2 and ST3 in humans, followed by other STs in minor percentages, with values of 33, 22, 38 and 7\%, respectively (Fig. 3), in agreement with the values reported in a previous study [9]. The countries included in this review had shown in Argentina the highest number of samples were positive for ST3 (Figs. 2, 3) [13], Bolivia showed the presence of ST9 and ST12, being the only country that presents these subtypes in North and South America. The USA was the only country that detected ST5 $[33,44]$. Brazil had a highest prevalence of $\mathrm{ST} 7$, but this subtype was also identified in Mexican and Colombian samples [9, 10, 23, 27, $28,50]$. Interestingly, Colombia is one of the countries where a greater variety of genetic variation is seen, and where the presence of almost all subtypes was found.

ST8 has only been found in marsupials ( $D$. marsupialis) and ST6 was found in both in humans and birds in Brazil $[9,10,23,27,50]$. In Chile, ST1, ST2 and ST4 were identified, although studies in this country have only been conducted in humans [38]. One of the few countries where ST8 was detected is Ecuador, in Alouatta monkeys [39]. Of note, the USA reports on a genetic variant known as 'Novel ST' (ST21, 23-26) and is the only country where 
ST14 and 17 were found in cattle [36, 40, 44]. In Mexico ST1, ST2 and ST7 were identified in Blastocystis-positive samples (Fig. 2) [9, 50].

In other parts of the world such as Europe, the most abundant STs recorded were ST3 and ST4 $[8,60]$, and the present study identified these subtypes at prevalences of $38 \%$ and $1.7 \%$, respectively, although there is disagreement about ST4, which in our analysis was the fourth most common subtype. The possibility exists that the ST3 is associated with transmission in humans because of the large quantity of positive samples and because the infections reported result from human-to-human transmission; nonetheless, ST3 has spread in non-human species that are in contact with people (e.g. cats and cattle) $[2,44,45]$. Therefore, the hypothesis of ST3 being of human origin is not supported by the present study, but it is the most abundant subtype in humans from North and South America.

Although previous studies reported that ST4 is only present in Colombia, it has since been identified in Brazil, Chile and the USA, suggesting that the patterns of transmission for Blastocystis have allowed it to spread geographically, and also that there is insufficient documentation on the presence of this subtype in North and South America [30, 35, 42]. According to the hypothesis of Ramirez et al. [9], ST4 is considered a minor infection in continental American animals because of the specific pathogen-host interactions on this continent or genetic characteristics as not yet known, in addition to the lack of studies on this premise. As the samples from which this subtype arose were from Colombia, Brazil, Chile and the USA, it is possible that this ST was carried by migration from the European continent to America by infected individuals who had visited these countries. This might explain the slight increase in infected individuals observed in the present study over previous studies, and it might also explain the appearance of this subtype in new countries where it has not been reported before, such as Brazil, Chile and the USA. Furthermore, its occurrence rates in animals such as monkeys (Alouatta spp.) and cattle in the actual studies under review were based on very few samples, making it difficult to establish reliable associations about ST4 and its hosts. However, it cannot be ruled out that these host animals may have some degree of genetic susceptibility to ST4 infections or might even have had their infections transmitted to them by infected humans. It would be interesting to establish whether the microbiome composition of the host animals might influence which subtypes infects them.

As for Novel ST, our review found that it is not present across North and South American countries, but studies on this ST have been performed in the USA to determine whether genetic differences exist between samples that fall within this ST. Hence, the term 'Novel ST' is now being replaced by numbers that follow ST17 by some authors, and this new numbering applies to cattle in the different states of the USA. Specifically, ST26 was the most frequently found ST in four US states (Michigan, New York, Washington and Wisconsin) and ST24 was found in two states (California, New York) (Fig. 2) [44]. This indicates that it is necessary to conduct further studies to corroborate the genetic diversity in the newly emerging subtypes at the molecular level and investigate whether they are present in other species and in other countries. Clearly, it is now important to harmonize the current nomenclature used in this field because some STs have been reported using different regions of the $18 S$ gene and not the consensus one reported by Scicluna et al. [60]. Concerningly, the entire $18 S$ has not been sequenced to demonstrate they are true novel STs. Future studies should consider sequencing the entire $18 \mathrm{~S}$ in order to place them as truly new STs or just variants of the currently known STs. In fact, we sequenced the entire $18 S$ region of those called "Novel STs" reported by Ramírez et al. [9] and found these were variants of ST6 and ST8.

\section{Conclusions}

In recent years, a variety of molecular epidemiological studies have been conducted on Blastocystis to identify its subtypes in the different countries from North and South America, but there is still too little data to elucidate the circulating subtypes and ribosomal alleles in these regions. It is important to highlight that the vast biodiversity on this continent could be shaping the emergence of new STs. We encourage the scientific community to commence subtyping this protist in several domestic and wild animals to obtain a better picture of Blastocystis in the region. We critically suggest that action should be taken regarding whether the new subtypes reported are in fact new subtypes or just variants, sequence artefacts, etc. Scientists in the Blastocystis community share the responsibility to not confuse and mix-up Blastocystis terminology. We finally call for action from researchers working on intestinal parasitism to start depicting the Blastocystis STs across the whole American continent (mainly Central American countries where information is lacking) to complement the maps and STs distribution presented herein.

\section{Additional file}

Additional file 1: Table S1. Microsoft Excel database assembly of all the information from the articles included in this review. 


\section{Abbreviations}

OTU: operational taxonomic units; STs: ribosomal subtypes.

\section{Acknowledgements}

We thank Sandra Cheesman from Edanz Group (http://www.edanzediti ng.com/ac) for editing a draft of this manuscript. We also thank Giovanny Herrera for his help in the construction of the maps.

\section{Authors' contributions}

PJ and JJ conducted the summary review and drafted the manuscript. JDR revised the final database and the manuscript. All authors read and approved the final manuscript.

\section{Funding}

Not applicable.

\section{Availability of data and materials}

The dataset used in the present review is summarized in Additional file 1: Table S1.

\section{Ethics approval and consent to participate}

Not applicable.

\section{Consent for publication}

Not applicable.

\section{Competing interests}

The authors declare that they have no competing interests.

\section{Author details}

${ }^{1}$ Grupo de Investigaciones Microbiológicas-UR (GIMUR), Departamento de Biología, Facultad de Ciencias Naturales y Matemáticas, Universidad del Rosario, Bogotá, Colombia. ${ }^{2}$ Escuela de Medicina y Ciencias de la Salud, Universidad del Rosario, Bogotá, Colombia.

Received: 28 March 2019 Accepted: 25 July 2019

Published online: 29 July 2019

\section{References}

1. Clark CG, Van der Giezen M, Alfellani MA, Stensvold CR. Recent developments in Blastocystis research. Adv Parasitol. 2013;82:1-32.

2. Ramírez JD, Sánchez LV, Bautista DC, Corredor AF, Flórez AC, Stensvold CR Blastocystis subtypes detected in humans and animals from Colombia. Infect Genet Evol. 2014;22:223-8.

3. Yoshikawa H, Yoshida K, Nakajima A, Yamanari K, Iwatani S, Kimata I. Fecaloral transmission of the cyst form of Blastocystis hominis in rats. Parasitol Res. 2004;94:391-6.

4. Stensvold CR, Arendrup MC, Jespersgaard C, Molbak K, Nielsen HV. Detecting Blastocystis using parasitologic and DNA-based methods: a comparative study. Diagn Microbiol Infect Dis. 2007;59:303-7.

5. Tan KSW. New insights on classification, identification, and clinical relevance of Blastocystis spp. 2008;21:639-65

6. Dogruman-Al F, Kustimur S, Yoshikawa H, Tuncer C, Simsek Z, Tanyuksel M, et al. Blastocystis subtypes in irritable bowel syndrome and inflammatory bowel disease in Ankara, Turkey. Mem Inst Oswaldo Cruz. 2009:104:724-7.

7. Alfellani MA, Taner-Mulla D, Jacob AS, Imeede CA, Yoshikawa H, Stensvold CR, et al. Genetic diversity of Blastocystis in livestock and zoo animals. Protist. 2013;164:497-509.

8. Stensvold CR, Christiansen DB, Olsen KEP, Nielsen HV. Blastocystis sp subtype 4 is common in Danish Blastocystis-positive patients presenting with acute diarrhea. Am J Trop Med Hyg. 2011;84:883-5.

9. Ramirez JD, Sanchez A, Hernandez C, Florez C, Consuelo Bernal M, Cesar Giraldo J, et al. Geographic distribution of human Blastocystis subtypes in South America. Infect Genet Evol. 2016;41:32-5.

10. Ramírez JD, Flórez C, Olivera M, Bernal MC, Giraldo JC. Blastocystis subtyping and its association with intestinal parasites in children from different geographical regions of Colombia. PLoS ONE. 2017;12:e0172586.
11. Melo GB, Paula FM, Malta FM, Maruta CW, Criado PR, Castilho VLP, et al. Identification of Blastocystis subtypes in clinical stool samples from Sao Paulo City, Brazil. Parasitol Open. 2017;3:e3.

12. Rojas-Velázquez L, Morán P, Serrano-Vázquez A, Fernández LD, PérezJuárez H, Poot- Hernández AC, et al. Genetic diversity and distribution of Blastocystis subtype 3 in human populations, with special reference to a rural population in Central Mexico. Biomed Res Int. 2018;2018:3916263.

13. Casero RD, Mongi F, Sánchez A, Ramírez JD. Blastocystis and urticaria: examination of subtypes and morphotypes in an unusual clinical manifestation. Acta Trop. 2015;148:156-61.

14. Nieves-Ramirez ME, Partida-Rodriguez O, Laforest-Lapointe I, Reynolds LA Brown EM, Valdez-Salazar A, et al. Asymptomatic intestinal colonization with protist Blastocystis is strongly associated with distinct microbiome ecological patterns. mSystems. 2018;3:e00007-18.

15. Beghini F, Pasolli E, Truong TD, Segata N, Putignani L, Cacciò SM. Largescale comparative metagenomics of Blastocystis, a common member of the human gut microbiome. ISME J. 2017;11:2848-63.

16. Forsell J, Bengtsson-Palme J, Angelin $\mathrm{M}$, Johansson A, Evengård B, Granlund $M$. The relation between Blastocystis and the intestinal microbiota in Swedish travellers. BMC Microbiol. 2017;17:231.

17. Nash AK, Auchtung TA, Wong MC, Smith DP, Gesell JR, Ross MC, et al. The gut mycobiome of the human microbiome project healthy cohort. Microbiome. 2017;5:153.

18. Andersen LOB, Stensvold CR. Blastocystis in health and disease: are we moving from a clinical to a public health perspective? J Clin Microbiol. 2016;54:524-8.

19. Lepczyńska M, Białkowska J, Dzika E, Piskorz-Ogórek K, Korycińska J. Blastocystis: how do specific diets and human gut microbiota affect its development and pathogenicity? Eur J Clin Microbiol Infect Dis. 2017;36:1531-40

20. Stensvold CR. Pinning down the role of common luminal intestinal parasitic protists in human health and disease — status and challenges. Parasitology. 2019;146:695-701.

21. Barbosa CV, de Batista R, Igreja RP, Levy CM, de Macedo HW, Santos HL. Distribution of Blastocystis subtypes isolated from humans from an urban community in Rio de Janeiro, Brazil. Parasit Vectors. 2017;10:518.

22. Barbosa CV, Barreto MM, Andrade RJ, Sodré F, d'Avila-Levy CM, Peralta JM, et al. Intestinal parasite infections in a rural community of Rio de Janeiro (Brazil): prevalence and genetic diversity of Blastocystis subtypes. PLoS ONE. 2018;13:e0193860.

23. David EB, Guimarães S, de Oliveira AP, de Oliveira-Sequeira TC, Bittencourt NG, Nardi AR, et al. Molecular characterization of intestinal protozoa in two poor communities in the State of São Paulo, Brazil. Parasit Vectors. 2015;8:103.

24. Malheiros AF, Stensvold CR, Clark CG, Braga GB, Shaw JJ. Molecular characterization of Blastocystis obtained from members of the indigenous Tapirape ethnic group from the Brazilian Amazon region, Brazil. Am J Trop Med Hyg. 2011;85:1050-3.

25. Melo G, Paula F, Malta F, Maruta C, Criado P, Castilho V, et al. Molecular characterization of Blastocystis sp. in chronic urticaria patients, Sao Paulo, Brazil. 2nd International Blastocystis Conference, October 9-12th, Bogota, Colombia; 2019.

26. Moura RGF, Oliveira-Silva MB, Pedrosa AL, Nascentes GAN, Cabrine-Santos M. Occurrence of Blastocystis spp in domestic animals in Triângulo Mineiro area of Brazil. Rev Soc Bras Med Trop. 2015;51:240-3.

27. Oliveira-Arbex AP, David ÉB, Guimarães S. Blastocystis genetic diversity among children of low-income daycare center in southeastern Brazil. Infect Genet Evol. 2018;57:59-63.

28. Satin M, Rodruigues da Cunha MJ, Maloney JG, Cury MC. Widespread presence of human - pathogenic Blastocystis subtypes in chickens. 2nd International Blastocystis Conference, October 9-12th, Bogota, Colombia; 2019.

29. Seguí R, Klisiowicz D, Oishi CY, Toledo R, Esteban JG, Muñoz-Antoli C. Intestinal symptoms and Blastocystis load in schoolchildren of Paranaguá Bay, Paraná, Brazil. Rev Inst Med Trop São Paulo. 2017;59:e86.

30. Seguí R, Muñoz-Antoli C, Klisiowicz DR, Oishi CY, Köster PC, de Lucio A, et al. Prevalence of intestinal parasites, with emphasis on the molecular epidemiology of Giardia duodenalis and Blastocystis sp, in the Paranaguá Bay, Brazil: a community survey. Parasit Vectors. 2018;11:490.

31. Seguí R, Klisiowicz D, Oishi C, Esteban G, Köster P, Carmena D, et al. Molecular characterization of Blastocystis sp. in Campo do Tenente (Curitiba, 
Paraná, Brasil). 2nd International Blastocystis Conference, October 9-12th, Bogota, Colombia; 2019.

32. Macchioni F, Segundo H, Gonzales PR, Salazar E, Bozo R, Gabrielli S, et al. Dramatic decrease in prevalence of soil-transmitted helminths and new insights into intestinal protozoa in children living in the Chaco Region, Bolivia. Am J Trop Med Hyg. 2015;92:794-6.

33. Macchioni F, Segundo H, Totino V, Gabrielli S, Rojas P, Roselli M, et al, Intestinal parasitic infections and associated epidemiological drivers in two rural communities of the Bolivian Chaco. J Infect Dev Ctries. 2016;10:1012-9.

34. Potes C, Osorio L, Carranza JC, Vallejo GA. Detection and molecular characterisation of Blastocystis spp. in human faecal samples from Igagué, Colombia. 2nd International Blastocystis Conference, October 9-12th, Bogota, Colombia; 2019.

35. Sánchez A, Munoz M, Gómez N, Tabares J, Segura L, Salazar Á, Restrepo C, Ruíz M, Reyes P, Qian Y, Xiao L, López MC, Ramírez JD. Molecular epidemiology of Giardia, Blastocystis and Cryptosporidium among indigenous children from the Colombian Amazon Basin. Front Microbiol. 2017;8:248.

36. Santin M, Teresa Gomez-Munoz M, Solano-Aguilar G, Fayer R. Development of a new PCR protocol to detect and subtype Blastocystis spp. from humans and animals. Parasitol Res. 2011;109:205-12.

37. Villamizae X, Vasquez L, Ramirez JD. Prevalence of Blastocystis in children and canine population of the commune eight of Popayán (Cauca, Colombia). 2nd International Blastocystis Conference, October 9-12th, Bogota, Colombia; 2019

38. Peña S, Carrasco G, Rojas P, Gotteland M, Castillo D, Ozaki LS, et al. Different subtypes of Blastocystis hominis (ST1, ST2 and ST4) are present in Chilean patients with inflammatory bowel disease. 2nd International Blastocystis Conference, October 9-12th, Bogota, Colombia; 2019.

39. Helenbrook WD, Shields WM, Whipps CM. Characterization of Blastocystis species infection in humans and mantled howler monkeys, Alouatta palliata aequatorialis, living in close proximity to one another. Parasitol Res. 2015;114:2517-25.

40. Fayer R, Santin M, Macarisin D. Detection of concurrent infection of dairy cattle with Blastocystis, Cryptosporidium, Giardia, and Enterocytozoon by molecular and microscopic methods. Parasitol Res. 2012;111:1349-55.

41. Fayer R, Elsasser T, Gould R, Solano G, Urban J, Santin M. Blastocystis tropism in the pig intestine. Parasitol Res. 2014;113:1465-72.

42. Jones MS 2nd, Ganac RD, Hiser G, Hudson NR, Le A, Whipps CM. Detection of Blastocystis from stool samples using real-time PCR. Parasitol Res. 2008;103:551-7.

43. Jones MS, Whipps CM, Ganac RD, Hudson NR, Boorom K. Association of Blastocystis subtype 3 and 1 with patients from an Oregon community presenting with chronic gastrointestinal illness. Parasitol Res. 2009;104:341-5.

44. Maloney JG, Lombard JE, Urie NJ, Shivley CB, Santin M. Zoonotic and genetically diverse subtypes of Blastocystis in US pre-weaned dairy heifer calves. Parasitol Res. 2018;2:575-82.

45. Ruaux CG, Stang B. Prevalence of Blastocystis in shelter-resident and client-owned companion animals in the US Pacific Northwest. PLoS ONE. 2014;9:e107496.

46. Scanlan PD, Knight R, Song SJ, Ackermann G, Cotter PD. Prevalence and genetic diversity of Blastocystis in family units living in the United States. Infect Genet Evol. 2016;45:95-7.
47. Whipps CM, Boorom K, Bermudez LE, Kent ML. Molecular characterization of Blastocystis species in Oregon identifies multiple subtypes. Parasitol Res. 2010;106:827-32.

48. Villegas-Gómez I, Martínez-Hernández F, Urrea-Quezada A, González-Díaz M, Durazo M, Hernández J, et al. Comparison of the genetic variability of Blastocystis subtypes between human carriers from two contrasting climatic regions of Mexico. Infect Genet Evol. 2016;44:334-40.

49. Villalobos G, Orozco-Mosqueda GE, Lopez-Perez M, Lopez-Escamilla E, Córdoba-Aguilar A, Rangel-Gamboa L, et al. Suitability of internal transcribed spacers (ITS) as markers for the population genetic structure of Blastocystis spp. Parasit Vectors. 2014;7:461.

50. Alarcon-Valdes P, Villalobos G, Martinez-Flores WA, Lopez-Escamilla E, Gonzalez-Arenas NR, Romero-Valdovinos M, et al. Can the pyruvate: ferredoxin oxidoreductase (PFOR) gene be used as an additional marker to discriminate among Blastocystis strains or subtypes? Parasit Vectors. 2018;11:564.

51. Stensvold CR, Clark CG. Current status of Blastocystis: a personal view. Parasitol Int. 2016;65:763-71.

52. Tan TC, Suresh KG. Predominance of amoeboid forms of Blastocystis hominis in isolates from symptomatic patients. Parasitol Res. 2006;98:189-93.

53. Hisao Y, Zhiliang W, Isao N, Yuzo T. Molecular comparative studies among Blastocystis isolates obtained from humans and animals. J Parasitol. 2003;89:585-95.

54. Li L-H, Zhou X-N, Du Z-W, Wang X-Z, Wang L-B, Jiang J-Y, et al. Molecular epidemiology of human Blastocystis in a village in Yunnan province, China. Parasitol Int. 2007;56:281-6.

55. Yoshikawa H, Wu Z, Pandey K, Pandey BD, Sherchand JB, Yanagi T, et al. Molecular characterization of Blastocystis isolates from children and rhesus monkeys in Kathmandu, Nepal. Vet Parasitol. 2009;160:295-300.

56. Forsell J, Granlund M, Samuelsson L, Koskiniemi S, Edebro H, Evengard B. High occurrence of Blastocystis sp. subtypes 1-3 and Giardia intestinalis assemblage $B$ among patients in Zanzibar, Tanzania. Vet Parasitol. 2016;1:370.

57. del Coco VF, Molina NB, Basualdo JA, Córdoba MA. Blastocystis spp: advances, controversies and future challenges. Rev Argent Microbiol. 2017:49:110-8.

58. El Safadi D, Osman M, Mallat H, Dabboussi F, Hamze M, Meloni D, et al. Molecular epidemiology of Blastocystis in Lebanon and correlation between subtype 1 and gastrointestinal symptoms. Am J Trop Med Hyg. 2013;88:1203-6.

59. El Safadi D, Gaayeb L, Meloni D, Cian A, Poirier P, Wawrzyniak I, et al. Children of Senegal River Basin show the highest prevalence of Blastocystis sp ever observed worldwide. BMC Infect Dis. 2014;14:164.

60. Scicluna SM, Tawari B, Clark CG. DNA barcoding of Blastocystis. Protist. 2006;1:77-85.

\section{Publisher's Note}

Springer Nature remains neutral with regard to jurisdictional claims in published maps and institutional affiliations.

Ready to submit your research? Choose BMC and benefit from

- fast, convenient online submission

- thorough peer review by experienced researchers in your field

- rapid publication on acceptance

- support for research data, including large and complex data types

- gold Open Access which fosters wider collaboration and increased citations

- maximum visibility for your research: over $100 \mathrm{M}$ website views per year

At BMC, research is always in progress.

Learn more biomedcentral.com/submissions 